\title{
High glypican-1 expression is a prognostic factor for predicting a poor clinical prognosis in patients with hepatocellular carcinoma
}

\author{
GUOYONG CHEN ${ }^{1}$, HAO WU ${ }^{2}$, LEI ZHANG ${ }^{3}$ and SIDONG WEI ${ }^{1}$ \\ ${ }^{1}$ Department of Hepatobiliary Surgery, Henan Provincial People's Hospital, School of Clinical Medicine, Henan University, \\ Zhengzhou, Henan 450003; ${ }^{2}$ Department of Hepatobiliary Surgery, The Second Affiliated Hospital of Chongqing Medical \\ University, Chongqing 400010; \\ ${ }^{3}$ Department of Hepatobiliary Surgery, Fengjie People's Hospital, Chongqing 404600, P.R. China
}

Received February 5, 2020; Accepted July 31, 2020

DOI: $10.3892 / \mathrm{ol} .2020 .12058$

\begin{abstract}
Hepatocellular carcinoma (HCC) has a high mortality rate, which imposes a huge burden on patients and society. Glypican-1 (GPC1) is considered to be an ideal diagnostic marker. The present study aimed to investigate GPC1 expression in $\mathrm{HCC}$, its association with clinicopathological factors and its prognostic significance in HCC progression. Reverse transcription-quantitative PCR, western blotting and immunohistochemical staining were used to investigate GPC1 expression in $175 \mathrm{HCC}$ and paired normal tissues, and in HCC and normal cells. Serolo2gical levels of GPC1 were examined via enzyme-linked immunosorbent assay in patients with HCC. Kaplan-Meier survival analysis and Cox regression analysis were used to assess the prognostic significance of GPC1. The present results suggested that GPC1 expression was upregulated in HCC tissues, especially in metastatic HCC. Similar results were observed in HCC cell lines. Serum GPC1 was higher in patients with HCC than in healthy controls (HCs). Patients with high GPC1 expression had shorter recurrence-free survival (RFS) and disease-specific survival (DSS) times compared with those with low GPC1 expression. In addition, high GPC1 expression was significantly associated with tumor size and Tumor-Node-Metastasis (TNM) stage $(\mathrm{P}<0.05)$. Furthermore, tumor size, TNM stage and GPC1 expression were independent predictive factors for RFS and DSS in patients with HCC. In conclusion, the present results revealed that high GPC1 expression was closely associated
\end{abstract}

Correspondence to: Professor Lei Zhang, Department of Hepatobiliary Surgery, Fengjie People's Hospital, 293 Kuizhou Road, Yong'an, Chongqing 404600, P.R. China

E-mail: 841450676@qq.com

Professor Sidong Wei, Department of Hepatobiliary Surgery, Henan Provincial People's Hospital, School of Clinical Medicine, Henan University, 7 Weiwu Road, Zhengzhou, Henan 450003, P.R. China E-mail: weisidongyishi@126.com

Key words: glypican-1, enzyme-linked immunosorbent assay, immunohistochemistry, hepatocellular carcinoma, prognostic factor with a poor prognosis in patients with HCC and that it may therefore be used as a potential target for accurate diagnosis and treatment of $\mathrm{HCC}$.

\section{Introduction}

Hepatocellular carcinoma (HCC) is the sixth most common tumor among all malignant tumors worldwide, but its mortality rate was the second highest among all malignant tumors in 2015 (1). More than half of all HCC cases and HCC-associated deaths occur in China (2). Patients with HCC often have viral cirrhosis background, and their liver function and liver reserve are abnormal and damaged (3). In China, only 30-40\% of patients with HCC have the opportunity to undergo radical tumor resection (4). Therefore, it is of great clinical importance to identify specific early diagnostic indicators for HCC to improve the therapeutic efficacy in HCC, as well as the overall prognosis and quality of life of patients with HCC.

Glypican-1 (GPC1) is a member of the phosphatidylinositol family (GPC1-6) and is a heparan sulfate glycoprotein that is anchored to the outer cell membrane by binding to the C-terminus of glycosylphosphatidyl alcohol (5). Melo et al (6) studied GPC1 expression in the peripheral blood of 190 patients with pancreatic ductal adenocarcinoma and 100 healthy volunteers; it was revealed that GPC1 was highly expressed in patients with cancer compared with healthy volunteers, and the larger the diameter and volume of the tumor, the higher the positive rate of GPC1 detected. The specificity and sensitivity of GPC1 in the diagnosis of early pancreatic cancer reached $100 \%$, suggesting that it is an ideal early marker of pancreatic cancer (6). Another study demonstrated that $75 \%$ (24/32) of patients with pancreatic cancer exhibited positive GPC1 expression in the peripheral blood, suggesting that GPC1 is upregulated in patients with pancreatic cancer, as well as in other types of tumor (6-8). Furthermore, GPC1 circulating exosomes (crExos) can be used for the early diagnosis and treatment of pancreatic cancer, and GPC1 crExos in pancreatic precancerous lesions was significantly increased compared with normal pancreatic tissues (9). However, the expression pattern of GPC-1 in patients with HCC remains unclear. Therefore, the association between GPC-1 expression and malignant development of HCC remains to be further studied. 
In the present study, GPC1 expression was investigated in HCC tissues and cell lines and was detected in the peripheral circulation of patients with HCC. In addition, the association between GPC1 expression in HCC and the survival rate and clinical prognosis in patients with HCC was analyzed.

\section{Materials and methods}

Patients and tissue samples. HCC tissues, paired adjacent tissues (distance from tumor tissue is $>5 \mathrm{~cm}$ ) and peripheral blood samples were collected from 175 patients with HCC who underwent surgical resection at The Second Affiliated Hospital of Chongqing Medical University (Chongqing, China) between October 2011 and May 2013 (mean age, 64 years; age range, 32-81 years; 94 males and 81 females) (Table I). In addition, 27 hepatic hemangioma $(\mathrm{HH})$ and 27 healthy control (HC) samples (the HC tissues were not from the same patients) were collected at The Second Affiliated Hospital of Chongqing Medical University (Chongqing, China). The corresponding clinicopathological data were obtained from The Second Affiliated Hospital of Chongqing Medical University (Chongqing, China). Patients with HCC were followed up to 5 years post-surgery to evaluate their survival rate. Patients were followed up by phone every 3 months and the total duration of follow up was 97 months. The present study was approved by the Ethics Committee of The Second Affiliated Hospital of Chongqing Medical University and was conducted in accordance with the Declaration of Helsinki.

Cell lines. The human HCC Hep3B, MHCC-97H, MHCC-97L and Huh-7 cell lines, and the normal liver THLE-2 cell line were obtained from The Cell Bank of Type Culture Collection of the Chinese Academy of Sciences. HCC cell lines were cultured in high-glucose DMEM with $10 \% \mathrm{FBS}$, and the normal liver THLE-2 cell line was cultured in Bronchial Epithelial Cell Growth Medium (BEGM) with 10\% FBS (all Gibco; Thermo Fisher Scientific, Inc.) and $100 \mathrm{U} / \mathrm{ml}$ penicillin and streptomycin All cells were cultured in a humidified incubator at $37^{\circ} \mathrm{C}$ with $5 \% \mathrm{CO}_{2}$.

Enzyme-linked immunosorbent assay (ELISA). Blood samples ( $5 \mathrm{ml}$ blood was collected) were centrifuged. The whole blood was kept for $30 \mathrm{~min}$ and centrifuged at 2,000 x g for $20 \mathrm{~min}$ at room temperature, and serum and plasma components were stored as aliquots at $-80^{\circ} \mathrm{C}$ until further use. An ELISA kit (cat. no. ELH-GPC1; RayBiotech, Inc.) was used to measure the levels of serum GPC1. According to the manufacturer's protocol, a monoclonal antibody specific for GPC1 was coated onto the wells of the microtiter strips. Subsequently, diluted samples, including standards of known GPC1 content, control specimens and unknowns, were pipetted into these wells, followed by the addition of a second biotinylated monoclonal antibody. Next, streptavidin-peroxidase was added to complete the four-member sandwich. After incubation at room temperature for $30 \mathrm{~min}$ and washing steps, the 3,3',5,5'-tetramethylbenzidine substrate solution was added, which reacted with the enzyme antibody-target complex to produce measurable signals. The optical density values were measured at $450 \mathrm{~nm}$ using a microplate reader (Bio- $\mathrm{Rad}$ Laboratories, Inc.).
$R N A$ extraction and reverse transcription-quantitative $(R T-q)$ $P C R$. Total RNA from HCC tissues, adjacent tissues, cell lines and $\mathrm{HH}$ tissues was extracted using TRIzol ${ }^{\circledR}$ reagent (Takara Bio, Inc.). PrimeScript RT reagent (Takara Bio, Inc.) was used for RT to cDNA, and RT-qPCR was performed using SYBR Premix Ex Taq II (Takara Bio, Inc.) using a LightCycler system (Roche Diagnostics). The temperature protocol for RT was as follows: $30^{\circ} \mathrm{C}$ for $10 \mathrm{~min}$, followed by $47^{\circ} \mathrm{C}$ for $40 \mathrm{~min}$ and $75^{\circ} \mathrm{C}$ for $30 \mathrm{~min}$. The primer sequences of GPC1 were as follows: Forward, 5'-CGGCCCCGCCATGGAGCTCC-3' and reverse, 5'-GGCAGTTACCGCCACCGGGG-3'. GAPDH forward, 5'-GCACCGTCAAGGCTGAGAAC-3' and reverse, 5'-TGG TGAAGACGCCAGTGGA-3'. The following thermocycling conditions were used for qPCR: Initial denaturation at $92^{\circ} \mathrm{C}$ for $10 \mathrm{~min}$, followed by 40 cycles of $95^{\circ} \mathrm{C}$ for $15 \mathrm{sec}$ and $65^{\circ} \mathrm{C}$ for $30 \mathrm{sec}$, and a final extension step at $72^{\circ} \mathrm{C}$ for $30 \mathrm{sec}$. GAPDH was used as an internal reference, and the mRNA expression levels of GPC1 were analyzed using the $2^{-\Delta \Delta C q}$ method (10).

Western blotting. Total protein from HCC cell lines, a normal liver cell line $\left(1 \times 10^{6}\right)$ and tissues (Hep3B, MHCC-97H, MHCC-97L, Huh-7, THLE-2 cell lines, HCC and paired adjacent tissues) was extracted using RIPA lysis buffer. Protein was quantified using the Bradford protein assay (Bio-Rad Laboratories, Inc.) with a Nanodrop spectrophotometer and an equal amount $(35 \mu \mathrm{g})$ was added to each well of $10 \%$ gels and resolved by SDS-PAGE. The samples were transferred to polyvinylidene difluoride membranes. The membranes were blocked with $5 \%$ skimmed milk powder at room temperature for $1 \mathrm{~h}$. Next, the membranes were probed at $4^{\circ} \mathrm{C}$ overnight, using the following primary antibodies: GPC1 (1:1,500; cat. no. ab199343; Abcam) and $\beta$-actin (1:5,000; cat. no. ab8227; Abcam). Subsequently, the membranes were incubated with a horseradish peroxidase-conjugated secondary antibody (1:5,000; cat. no. ab6721; Abcam) at room temperature for $1 \mathrm{~h}$. Protein bands were visualized using an enhanced chemiluminescence solution (EMD Millipore) and a ChemiDoc Imaging system (Bio-Rad Laboratories, Inc.). Protein expression was semi-quantified using the Quantity One v4.6.6 software (Bio-Rad Laboratories, Inc.). $\beta$-actin was used as an internal reference.

Immunohistochemical staining. The collected 175 HCC tissues were made into tissue microarrays. The tissue was fixed in $4 \%$ paraformaldehyde at room temperature for $24 \mathrm{~h}$ and embedded in paraffin. Sections were deparaffinized in xylene I for $15 \mathrm{~min}$ and xylene II for $15 \mathrm{~min}$ at $37^{\circ} \mathrm{C}$, and rehydrated in a graded ethanol series $(100,95,80$ and $75 \%$ ethanol for $5 \mathrm{~min}$ each). Subsequently, the sections were incubated with $3 \% \mathrm{H}_{2} \mathrm{O}_{2}$ for $30 \mathrm{~min}$ at $37^{\circ} \mathrm{C}$ and for $15 \mathrm{~min}$ at $37^{\circ} \mathrm{C}$ with $5 \%$ goat serum (Origene Technologies, Inc.) to block non-specific binding, followed by incubation with a rabbit monoclonal anti-GPC1 antibody (1:1,000; cat. no. ab55971; Abcam) at $4^{\circ} \mathrm{C}$ overnight. Next, the sections were incubated with an anti-rabbit secondary biotin labelled IgG antibody (1:100; cat. no. SAP-9100; Origene Technologies, Inc.) at $37^{\circ} \mathrm{C}$ for $30 \mathrm{~min}$. After washing with PBS, the visualization signal was detected using 3,3'-diaminobenzidine (Boster Biological Technology) and counterstaining was performed using hematoxylin at room temperature for $5 \mathrm{sec}$. 
Table I. Association between GPC1 expression and clinicopathological features of patients with hepatocellular carcinoma $(n=175)$.

\begin{tabular}{|c|c|c|c|c|}
\hline \multirow[b]{2}{*}{ Variables } & \multirow[b]{2}{*}{$\mathrm{N}$} & \multicolumn{2}{|c|}{ GPC1 expression } & \multirow[b]{2}{*}{ P-value } \\
\hline & & $\begin{array}{l}\text { Low } \\
(n=51)\end{array}$ & $\begin{array}{c}\text { High } \\
(n=124)\end{array}$ & \\
\hline Age, years & & & & 0.765 \\
\hline$<50$ & 82 & 23 & 59 & \\
\hline$\geq 50$ & 93 & 28 & 65 & \\
\hline Sex & & & & 0.895 \\
\hline Male & 94 & 27 & 67 & \\
\hline Female & 81 & 24 & 57 & \\
\hline Tumor size, cm & & & & 0.011 \\
\hline$\leq 5$ & 87 & 33 & 54 & \\
\hline$>5$ & 88 & 18 & 70 & \\
\hline AFP, ng/ml & & & & 0.456 \\
\hline$\leq 20$ & 68 & 22 & 46 & \\
\hline$>20$ & 107 & 29 & 78 & \\
\hline Liver cirrhosis & & & & 0.849 \\
\hline Present & 101 & 30 & 71 & \\
\hline Absent & 74 & 21 & 53 & \\
\hline HBsAg & & & & 0.883 \\
\hline Positive & 98 & 29 & 69 & \\
\hline Negative & 77 & 22 & 55 & \\
\hline TNM stage & & & & 0.033 \\
\hline $\mathrm{I} / \mathrm{II}$ & 81 & 30 & 51 & \\
\hline III/IV & 94 & 21 & 73 & \\
\hline Vascular invasion & & & & 0.520 \\
\hline Positive & 106 & 29 & 77 & \\
\hline Negative & 69 & 22 & 47 & \\
\hline Multiplicity & & & & 0.960 \\
\hline Single & 99 & 29 & 70 & \\
\hline Multiple ( $\geq 2)$ & 76 & 22 & 54 & \\
\hline Intrahepatic metastasis & & & & 0.532 \\
\hline Positive & 100 & 31 & 69 & \\
\hline Negative & 75 & 20 & 55 & \\
\hline
\end{tabular}

AFP, $\alpha$-fetoprotein; HBsAg, hepatitis B virus surface antigen; GPC1, glypican-1; TNM, Tumor-Node-Metastasis (29). Immunohistochemical staining score $<4$ were defined as low GPC 1 expression, while immunohistochemical staining score $\geq 4$ were defined as high GPC 1 expression.

GPC1 immunostaining was scored and examined by two double-blinded pathologists. All tissues observed using a light microscope at a magnification of x 200 were manually scored based on the percentage of positive cells and the intensity to determine the final staining scores. The scoring parameters included staining intensity (according to the color development degree of the positive markers; Light yellow, indicating weak positive; brown yellow, medium positive; and brown black, strong positive) (range, 0-3: 0, no staining; 1, weak; 2, moderate; and 3 , strong) and the percentage of positive cells (range, $0-4$ :
$0,<5 ; 1,6-25 ; 2,26-50 ; 3,51-75 ;$ and 4, 76-100\%). Slides with a total score $<4$ were defined as low GPC1 expression, while slides with a score $\geq 4$ were defined as high GPC1 expression.

Statistical analysis. The data were analyzed using SPSS v22.0 (IBM Corp.) and GraphPad Prism v6.0 (GraphPad Software, Inc.). GPC1 expression was presented as the mean \pm SD. All experiments were repeated 3 times. Statistical differences among multiple groups were analyzed using one-way ANOVA followed by Tukey's post hoc test. The significance of GPC1 was examined using paired or unpaired Student's t-test. The association between clinicopathological parameters and GPC1 expression was analyzed using $\chi^{2}$ test. Kaplan-Meier, log-rank tests and Cox regression for univariate and multivariate analysis were used to analyze the prognostic significance of GPC1 expression. RFS was recorded as the time from liver tumor resection removal to liver tumor recurrence. DSS was recorded as the time from cancer diagnosis to death from cancer or to the follow-up deadline. $\mathrm{P}<0.05$ was considered to indicate a statistically significant difference.

\section{Results}

GPCl expression in HCC tissues and cells. GPC1 expression in HCC tissues and cell lines was analyzed via RT-qPCR. The results revealed that GPC1 expression was significantly higher in HCC tissues compared with that in paired normal adjacent tissues $(\mathrm{P}<0.01$; Fig. 1A). Furthermore, GPC1 expression was significantly increased in aggressive HCC tissues (tumors with distant metastasis) compared with that in non-aggressive HCC tissues (tumors with no distant metastasis) $(\mathrm{P}<0.05$; Fig. 1B). However, there was no significant difference in the expression levels of GPC1 between $\mathrm{HH}$ and $\mathrm{HC}$ tissues ( $\mathrm{P}>0.05$; Fig. 1C). Western blotting results revealed that $\mathrm{GPC} 1$ protein expression was higher in HCC tissues compared with that in their paired normal adjacent tissues (Fig. 1D and E).

In addition, GPC1 expression was higher in HCC cell lines compared with that in the normal liver cell line and GPC1 expression was higher in cells with high malignancy (MHCC-97H cells had high metastatic ability compared with the other cell lines tested) (Fig. 2A and B).

Serum levels of GPCl in patients with HCC and HH, and in $H C s$. Subsequently, the serum levels of GPC1 were analyzed in $\mathrm{HCC}, \mathrm{HH}$ and $\mathrm{HC}$ samples. As shown in Fig. 3A, the serum levels of GPC1 in HCC samples were significantly higher than in $\mathrm{HC}$ samples $(\mathrm{P}<0.05)$. However, there was no significant difference in the serum levels of GPC1 between $\mathrm{HH}$ and $\mathrm{HC}$ samples $(\mathrm{P}>0.05$; Fig. 3B). Furthermore, higher serum levels of GPC1 were detected in stage III/IV HCC samples than in stage I/II HCC samples ( $\mathrm{P}<0.05$; Fig. $3 \mathrm{C}$ ). The serum levels of GPC1 were higher in tumors $>5 \mathrm{~cm}$ in size than in tumors $<5 \mathrm{~cm}$ in size. There was no significant difference between stage III/IV or $>5 \mathrm{~cm}$ in $\mathrm{HC}$ samples $(\mathrm{P}<0.05$; Fig. $3 \mathrm{D})$.

Associations between GPCl expression and clinicopathologicalfeatures in patients with HCC. The present results revealed that GPC1 expression was high in 124/175 HCC samples (70.9\%) and low in 51/175 HCC samples (29.1\%) (Table I), and GPC1 was mainly expressed in the cytoplasm and cell 

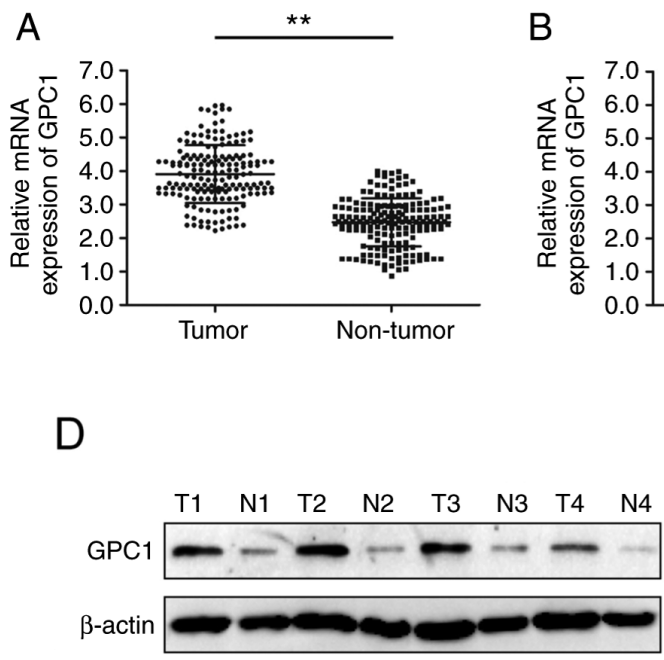

B

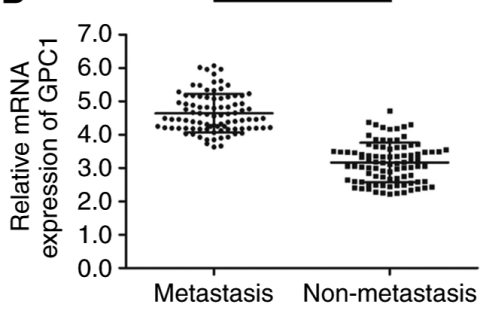

C

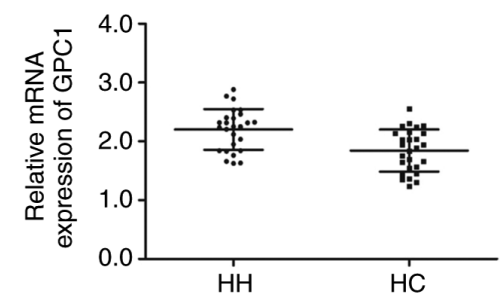

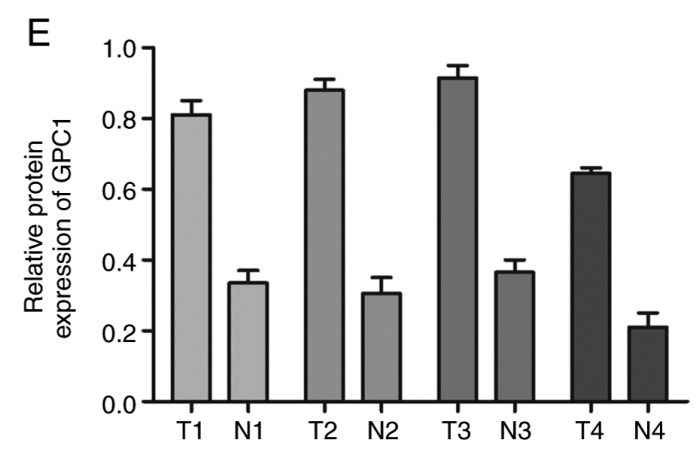

Figure 1. GPC1 expression in HCC, HH and HC tissues measured by reverse transcription-quantitative PCR and WB. (A) Relative mRNA expression of GPC1 in HCC and paired normal adjacent tissues. (B) Relative mRNA expression of GPC1 in aggressive (metastasis) and non-aggressive (non-metastasis) HCC tissues. (C) Relative mRNA expression of GPC1 in HH and HC tissues. (D) GPC1 protein expression in HCC and paired normal adjacent tissues analyzed via $\mathrm{WB}$ and $(\mathrm{E})$ its relative quantification. ${ }^{*} \mathrm{P}<0.05,{ }^{* *} \mathrm{P}<0.01$; analyzed by paired t-test (A) and unpaired t-test (B) and (C) HCC, hepatocellular carcinoma; WB, western blotting; HH, hepatic hemangioma; HC, healthy control; GPC1, glypican-1; T, tumor; N, non-tumor.

A

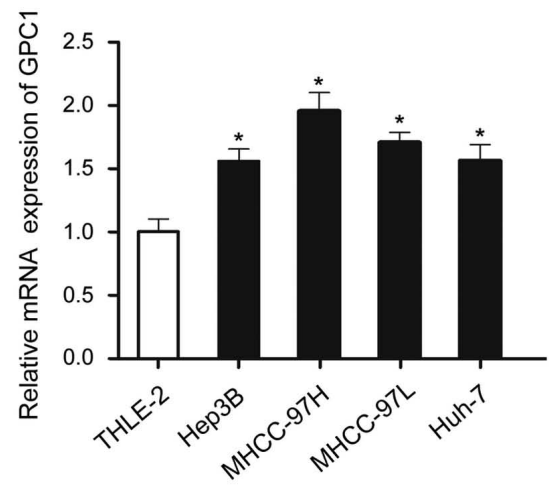

B

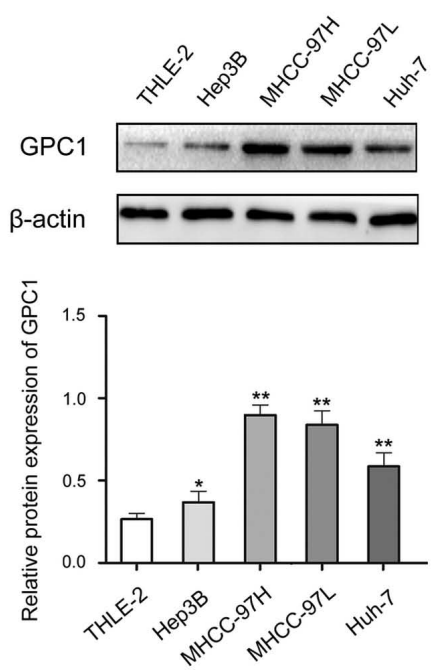

Figure 2. GPC1 expression in HCC and normal liver cells measured by reverse transcription-quantitative PCR and western blotting. (A) Relative mRNA expression of GPC1 in four HCC cell lines and the normal human liver THLE-2 cell line, which served as a control. (B) GPC1 protein expression in four HCC cell lines and the normal human hepatocyte cell line THLE-2, which served as a control. * $\mathrm{P}<0.05$ and ${ }^{* *} \mathrm{P}<0.01$ vs. THLE- 2 . HCC, hepatocellular carcinoma; GPC1, glypican-1.

membrane (Fig. 4A and B). As shown in Table I, GPC1 expression was positively associated with tumor size $(\mathrm{P}=0.011)$ and Tumor-Node-Metastasis (TNM) stage $(\mathrm{P}=0.033)$. However, there were no significant differences between GPC1 expression and age, sex, $\alpha$-fetoprotein levels, liver cirrhosis, hepatitis $B$ virus surface antigen, vascular invasion, multiplicity and intrahepatic metastasis (all $\mathrm{P}>0.05$; Table I).

Association between GPC1 expression and recurrence-free survival (RFS) in patients with HCC. Kaplan-Meier survival analysis revealed that the RFS time was significantly shorter in patients with HCC with high GPC1 expression compared with that in patients with low GPC1 expression in HCC $(\mathrm{P}=0.003$; Fig. 5A). In addition, the univariate analysis revealed that tumor size [hazard ratio $(\mathrm{HR})=1.561 ; \mathrm{P}=0.041$ ], TNM stage $(\mathrm{HR}=1.609 ; \mathrm{P}=0.019)$ and $\mathrm{GPC} 1$ expression $(\mathrm{HR}=1.579$; $\mathrm{P}=0.009$ ) were significantly associated with RFS in patients with HCC (Table II). The multivariate analysis revealed that tumor size $(\mathrm{HR}=1.773 ; \mathrm{P}=0.047)$, TNM stage $(\mathrm{HR}=1.473 ; \mathrm{P}=0.025)$ and $\mathrm{GPC} 1$ expression $(\mathrm{HR}=1.311 ; \mathrm{P}=0.007)$ were independent prognostic factors for RFS in patients with HCC (Table II).

Association between GPC1 expression and disease-specific survival (DSS) in patients with HCC. Kaplan-Meier survival 
A

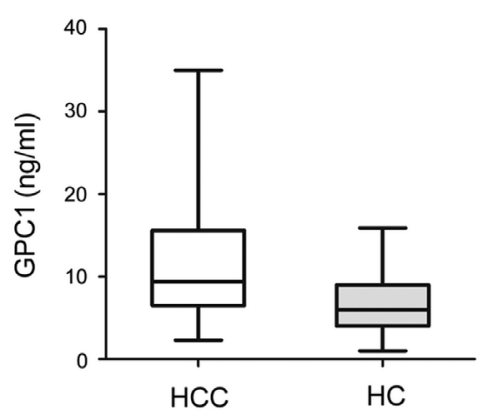

C

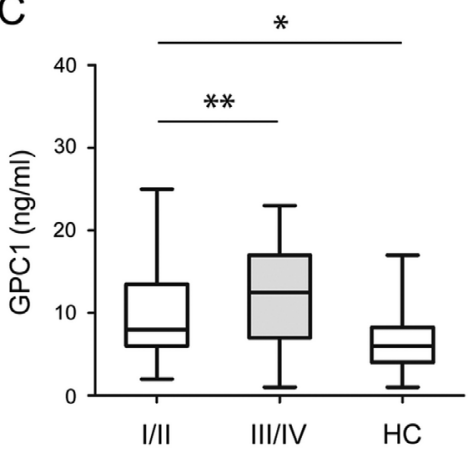

B

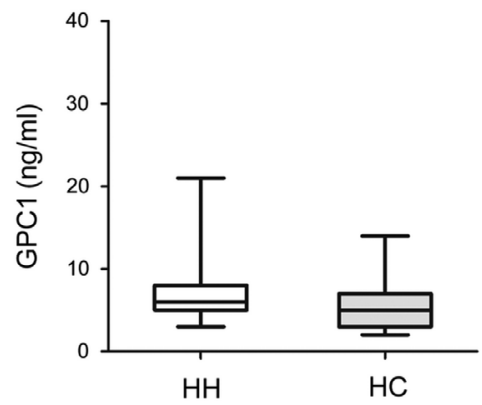

D

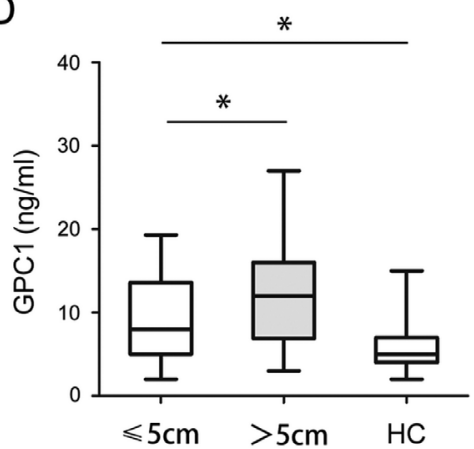

Figure 3. Serum levels of GPC1 in patients with HCC and HH, and in HCs measured via enzyme-linked immunosorbent assay. (A) Serum levels of GPC1 in HCC and HC samples. (B) Serum levels of GPC1 in HH and HC samples. (C) Serum levels of GPC1 in patients with different stage HCC. (D) Serum levels of GPC1 in patients with tumors of different sizes. ${ }^{*} \mathrm{P}<0.05,{ }^{* *} \mathrm{P}<0.01 ;$ (A) analyzed by paired Student's t-test; (B, C and D) analyzed by unpaired Student's t-test. HCC, hepatocellular carcinoma; HH, hepatic hemangioma; HC, healthy control; GPC1, glypican-1.

A
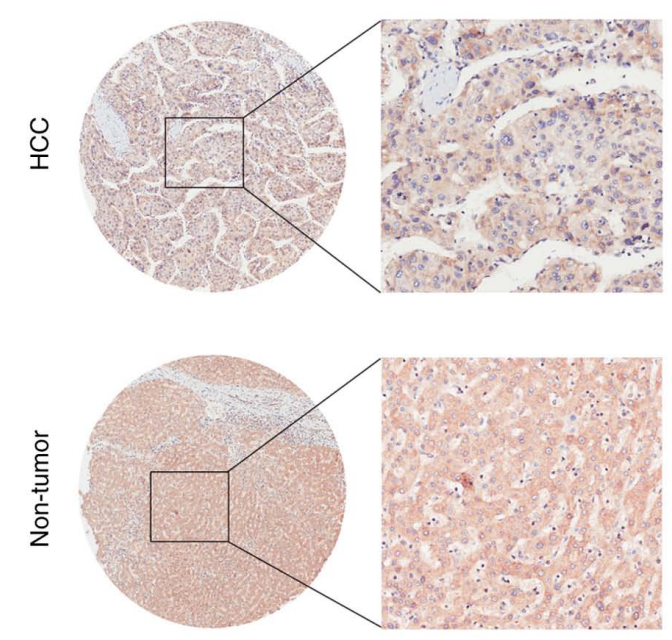

B
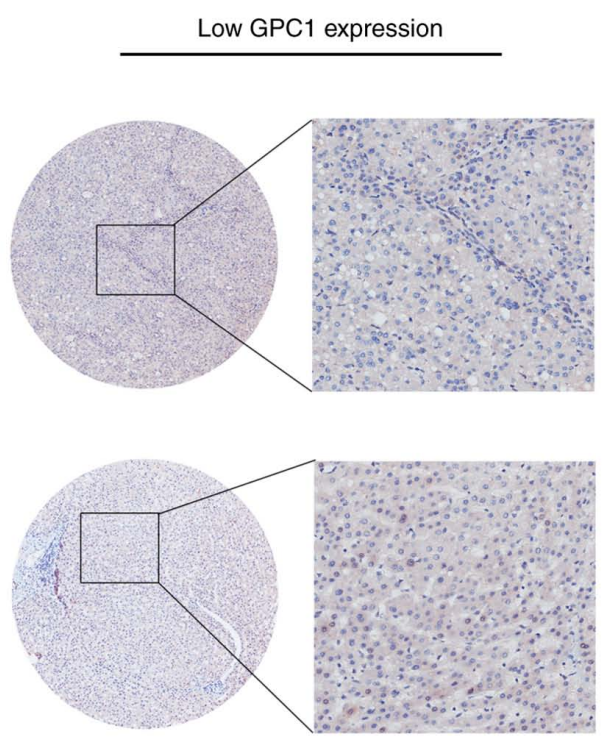

Figure 4. Immunohistochemical staining of GPC1 expression in HCC and paired non-tumor tissues. (A) High GPC1 expression in HCC and paired normal adjacent tissues. (B) Low GPC1 expression in HCC and paired normal adjacent tissues. Magnification, x50 and x200. HCC, hepatocellular carcinoma; GPC1, glypican-1.

analysis revealed that the DSS time was significantly shorter in patients with HCC with high GPC1 expression compared with that in patients with low GPC1 expression ( $\mathrm{P}=0.002$; Fig. 5B). In addition, the univariate analysis revealed that tumor size $(\mathrm{HR}=1.204 ; \mathrm{P}=0.039)$, TNM stage $(\mathrm{HR}=1.342 ; \mathrm{P}=0.022)$ and GPC1 expression $(\mathrm{HR}=1.770 ; \mathrm{P}=0.017)$ were significantly associated with DSS in patients with HCC (Table III). Similarly, the multivariate analysis revealed that tumor size
$(\mathrm{HR}=1.119 ; \mathrm{P}=0.031)$, TNM stage $(\mathrm{HR}=1.554 ; \mathrm{P}=0.028)$ and GPC1 expression $(\mathrm{HR}=1.883 ; \mathrm{P}=0.014)$ were independent prognostic factors for DSS in patients with HCC (Table III).

\section{Discussion}

In 2015, HCC was one of the most common malignant tumors globally (1). Poor prognosis is an important biological 
Table II. Univariate and multivariate analysis of different prognostic variables influencing recurrence-free survival in patients with hepatocellular carcinoma $(\mathrm{n}=175)$.

\begin{tabular}{|c|c|c|c|c|c|}
\hline \multirow[b]{2}{*}{ Variables } & \multirow[b]{2}{*}{$\mathrm{N}$} & \multicolumn{2}{|c|}{ Univariate analysis } & \multicolumn{2}{|c|}{ Multivariate analysis } \\
\hline & & $\mathrm{HR}(95 \% \mathrm{CI})$ & P-value & HR $(95 \%$ CI $)$ & P-value \\
\hline Sex & & $0.967(0.337-1.285)$ & 0.604 & & \\
\hline Male & 94 & & & & \\
\hline Female & 81 & & & & \\
\hline Age, years & & $0.618(0.590-1.844)$ & 0.594 & & \\
\hline$<50$ & 82 & & & & \\
\hline$\geq 50$ & 93 & & & & \\
\hline Tumor size, $\mathrm{cm}$ & & $1.561(0.864-2.349)$ & 0.041 & $1.773(0.617-1.968)$ & 0.047 \\
\hline$\leq 5$ & 87 & & & & \\
\hline$>5$ & 88 & & & & \\
\hline AFP, ng/ml & & $1.135(0.884-1.973)$ & 0483 & & \\
\hline$\leq 20$ & 68 & & & & \\
\hline$>20$ & 107 & & & & \\
\hline HBsAg & & $1.373(1.075-3.600)$ & 0.894 & & \\
\hline Positive & 98 & & & & \\
\hline Negative & 77 & & & & \\
\hline TNM stage & & $1.609(1.224-3.884)$ & 0.019 & $1.473(0.674-3.048)$ & 0.025 \\
\hline $\mathrm{I} / \mathrm{II}$ & 81 & & & & \\
\hline III/IV & 94 & & & & \\
\hline Liver cirrhosis & & $0.564(1.647-3.557)$ & 0.550 & & \\
\hline Present & 101 & & & & \\
\hline Absent & 74 & & & & \\
\hline Vascular invasion & & $0.667(1.478-3.647)$ & 0.664 & & \\
\hline Positive & 106 & & & & \\
\hline Negative & 69 & & & & \\
\hline Multiplicity & & $1.542(0.739-1.647)$ & 0.940 & & \\
\hline Single & 99 & & & & \\
\hline Multiple $(\geq 2)$ & 76 & & & & \\
\hline Intrahepatic metastasis & & $1.672(0.590-3.027)$ & 0.393 & & \\
\hline Positive & 100 & & & & \\
\hline Negative & 75 & & & & \\
\hline GPC1 expression & & $1.579(0.831-2.947)$ & 0.009 & $1.311(0.773-2.647)$ & 0.007 \\
\hline High & 124 & & & & \\
\hline Low & 51 & & & & \\
\hline
\end{tabular}

HR, hazard ratio; AFP, $\alpha$-fetoprotein; HBsAg, hepatitis B virus surface antigen; GPC1, glypican-1; TNM, Tumor-Node-Metastasis (29). Immunohistochemical staining score $<4$ were defined as low GPC1 expression, while immunohistochemical staining score $\geq 4$ were defined as high GPC1 expression.
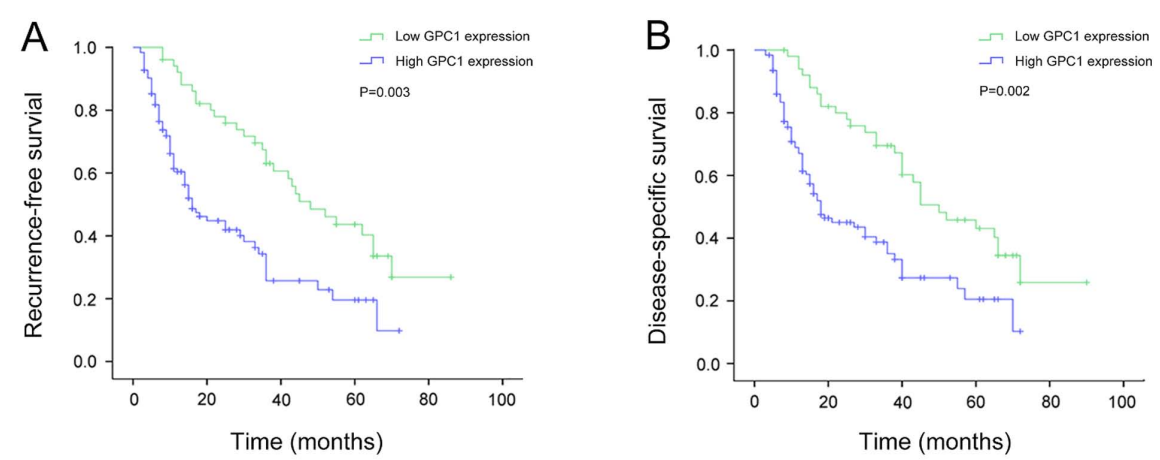

Figure 5. Kaplan-Meier survival curves of patients with HCC according to their GPC1 expression. (A) Kaplan-Meier analysis of recurrence-free survival between patients with HCC with high and low GPC1 expression. (B) Kaplan-Meier analysis of disease-specific survival between patients with HCC with high and low GPC1 expression. GPC1, glypican-1. 
Table III. Univariate and multivariate analysis of different prognostic variables influencing disease-specific survival in patients with hepatocellular carcinoma $(n=175)$.

\begin{tabular}{|c|c|c|c|c|c|}
\hline \multirow[b]{2}{*}{ Variables } & \multirow[b]{2}{*}{$\mathrm{N}$} & \multicolumn{2}{|c|}{ Univariate analysis } & \multicolumn{2}{|c|}{ Multivariate analysis } \\
\hline & & HR $(95 \% \mathrm{CI})$ & P-value & HR (95\% CI) & P-value \\
\hline Sex & & $0.704(0.507-1.132)$ & 0.589 & & \\
\hline Male & 94 & & & & \\
\hline Female & 81 & & & & \\
\hline Age, years & & $0.804(0.660-1.484)$ & 0.377 & & \\
\hline$<50$ & 82 & & & & \\
\hline$\geq 50$ & 93 & & & & \\
\hline Tumor size, $\mathrm{cm}$ & & $1.204(0.531-1.678)$ & 0.039 & $1.119(0.698-1.840)$ & 0.031 \\
\hline$\leq 5$ & 87 & & & & \\
\hline$>5$ & 88 & & & & \\
\hline AFP, ng/ml & & $0.947(1.337-2.607)$ & 0483 & & \\
\hline$\leq 20$ & 68 & & & & \\
\hline$>20$ & 107 & & & & \\
\hline HBsAg & & $1.078(0.576-1.628)$ & 0.631 & & \\
\hline Positive & 98 & & & & \\
\hline Negative & 77 & & & & \\
\hline TNM stage & & $1.342(0.931-2.741)$ & 0.022 & $1.554(0.846-2.478)$ & 0.028 \\
\hline $\mathrm{I} / \mathrm{II}$ & 81 & & & & \\
\hline III/IV & 94 & & & & \\
\hline Liver cirrhosis & & $1.360(0.874-2.337)$ & 0.981 & & \\
\hline Present & 101 & & & & \\
\hline Absent & 74 & & & & \\
\hline Vascular invasion & & $1.686(1.207-2.947)$ & 0.573 & & \\
\hline Positive & 106 & & & & \\
\hline Negative & 69 & & & & \\
\hline Multiplicity & & $0.884(0.514-1.972)$ & 0.830 & & \\
\hline Single & 99 & & & & \\
\hline Multiple ( $\geq 2)$ & 76 & & & & \\
\hline Intrahepatic metastasis & & $1.047(1.369-3.840)$ & 0.796 & & \\
\hline Positive & 100 & & & & \\
\hline Negative & 75 & & & & \\
\hline GPC1 expression & & $1.770(1.604-3.943)$ & 0.017 & $1.883(1.530-3.647)$ & 0.014 \\
\hline High & 124 & & & & \\
\hline Low & 51 & & & & \\
\hline
\end{tabular}

HR, hazard ratio; AFP, $\alpha$-fetoprotein; HBsAg, hepatitis B virus surface antigen; GPC1, glypican-1; TNM, Tumor-Node-Metastasis (29). Immunohistochemical staining score $<4$ were defined as low GPC1 expression, while immunohistochemical staining score $\geq 4$ were defined as high GPC1 expression.

characteristic of HCC (11). Notably, recurrence and metastasis of HCC remain the main causes of failure of HCC treatment, which imposes a heavy burden on families and society (3). Recent studies revealed that the cause of a poor prognosis in patients with HCC is a complex process, involving numerous regulatory factors, including genetic mutations, cell surface signaling molecules and adhesion changes caused by epigenetic changes in tumor cells and normal liver cells, abnormal cell metabolism and changes in tumor cells and their surrounding microenvironment $(12,13)$. Although existing treatments can improve the quality of life and survival time of patients with HCC, the overall survival rate of patients remains unsatisfactory (14). In the present study, the association between GPC1 expression and HCC was analyzed, and preliminarily explored the relationship between GPC1 and poor prognosis of patients with HCC. The current study provided objective scientific evidence and novel molecular targets for the diagnosis and treatment of HCC.

A study has demonstrated that GPC1 can act as a negative regulator of the sonic hedgehog signaling pathway during biliary development, and that low GPC1 expression leads to biliary developmental damage and biliary atresia (15). GPC1 inhibits metaphase and centrosome production and it mediates the activation of nitric oxide synthase to protect endothelial 
function (16-18). Since GPC1 serves an important role in the heparin-binding growth factors, Wnt and sonic hedgehog signaling pathways, it is widely involved in precancerous lesions of various types of pancreatic ductal adenocarcinoma (PDAC) and HCC (19-21). A large number of studies have demonstrated that GPC1 enhances the mitogenic responses of pancreatic ductal adenocarcinoma cells to fibroblast growth factor-2, heparin-binding epidermal growth factor and hepatocyte growth factor as a growth factor co-receptor, and serves a crucial role in the malignant progression of oesophageal squamous cell carcinoma and PDAC (22-24). Abnormal GPC1 upregulation was observed in glioma, prostate cancer and esophageal squamous cell carcinoma (5-7). Furthermore, GPC1 is considered as an important prognostic biomarker for PDAC (9). High GPC1 expression is associated with poorer differentiation and larger tumor diameters in PDAC, indicating that the abnormally high GPC1 expression may serve important roles in tumorigenesis (25).

It has been reported that GPC1 crExos in the circulatory system may serve as reliable targets for the early diagnosis of PDAC, and may be used to predict the progression and prognosis in patients with PDAC (26). Levels of GPC1 crExos in patients with histologically proven precursor pancreatic cancer and PDAC are significantly higher compared with those in patients with benign pancreatic disease and in healthy controls (26). Notably, even for early PDAC, GPC1 crExos exhibited almost $100 \%$ sensitivity and specificity, indicating its outstanding potential for the early detection of PDAC $(27,28)$.

The present findings in HCC are similar to those previously observed in PDAC. Tissue and blood samples were collected from patients with $\mathrm{HCC}$, and the expression levels of GPC1 were analyzed by western blotting, RT-qPCR, immunohistochemistry and ELISA. The current results revealed that GPC1 expression was significantly higher in HCC compared with matched adjacent tissues. Via analyzing the clinical features of patients with HCC with different expression levels of GPC1, it was demonstrated that GPC1 expression was associated with tumor size and TNM stage. Furthermore, patients with HCC with high GPC1 expression exhibited a poorer prognosis compared with patients with low GPC1 expression. GPC1 expression, TNM stage and tumor size appeared to be independent risk factors for RFS and DSS in patients with HCC. The present results demonstrated that GPC1 may be a potentially valuable biomarker to predict recurrence and survival in patients with $\mathrm{HCC}$. In addition, tumors of patients with HCC with high GPC1 expression may exhibit more malignant biological characteristics. In conclusion, the current results supported GPC1 as a molecular target for predicting, diagnosing and treating HCC. High GPC1 expression was closely associated with a poor prognosis in patients with HCC. Therefore, GPC1 may be used as an independent prognostic factor and a promising therapeutic target for HCC.

\section{Acknowledgements}

Not applicable.

\section{Funding}

The present study was supported by the Medical Science and Technology Program of Henan Province (grant no. SBGJ2018071) and Medical Research Projects of Chongqing Health and Family Planning Commission (grant no. 2017ZBXM070).

\section{Availability of data and materials}

All data generated or analyzed during this study are included in this published article.

\section{Author's contributions}

GC and SW designed the study, conducted the experiments and wrote the manuscript. LZ and HW provided the research materials and analyzed the data. All authors read and approved the final manuscript, and agree to be accountable for all aspects of the research.

\section{Ethics approval and consent to participate}

All protocols involving the use of humans were approved by the Ethics Review Committee of The Second Affiliated Hospital of Chongqing Medical University (approval no. 201105017). Written informed consent was provided by all patients for the use of their tissues in the present study.

\section{Patient consent for publication}

Not applicable.

\section{Competing interests}

The authors declare that they have no competing interests.

\section{References}

1. Grandhi MS, Kim AK, Ronnekleiv-Kelly SM, Kamel IR, Ghasebeh MA and Pawlik TM: Hepatocellular carcinoma: From diagnosis to treatment. Surg Oncol 25: 74-85, 2016.

2. Chen W, Zheng R, Baade PD, Zhang S, Zeng H, Bray F, Jemal A, Yu XQ and He J: Cancer statistics in China, 2015. CA Cancer J Clin 66: 115-132, 2016.

3. Wu H, Zhang W, Wu Z, Liu Y, Shi Y, Gong J, Shen W and Liu C: miR-29c-3p regulates DNMT3B and LATS1 methylation to inhibit tumor progression in hepatocellular carcinoma. Cell Death Dis 10: 48, 2019.

4. Ramalho M, Matos AP, AlObaidy M, Velloni F, Altun E and Semelka RC: Magnetic resonance imaging of the cirrhotic liver: Diagnosis of hepatocellular carcinoma and evaluation of response to treatment-Part 1. Radiol Bras 50: 38-47, 2017.

5. Hara H, Takahashi T, Serada S, Fujimoto M, Ohkawara T, Nakatsuka R, Harada E, Nishigaki T, Takahashi Y, Nojima S, et al: Overexpression of glypican-1 implicates poor prognosis and their chemoresistance in oesophageal squamous cell carcinoma. $\mathrm{Br} \mathrm{J}$ Cancer 115: 66-75, 2016.

6. Melo SA, Luecke LB, Kahlert C, Fernandez AF, Gammon ST, Kaye J, LeBleu VS, Mittendorf EA, Weitz J, Rahbari N, et al: Glypican-1 identifies cancer exosomes and detects early pancreatic cancer. Nature 523: 177-182, 2015.

7. Truong Q, Justiniano IO, Nocon AL, Soon JT, Wissmueller S, Campbell DH and Walsh BJ: Glypican-1 as a biomarker for prostate cancer: Isolation and characterization. J Cancer 7: 1002-1009, 2016

8. Herreros-Villanueva M and Bujanda L: Glypican-1 in exosomes as biomarker for early detection of pancreatic cancer. Ann Transl Med 4: 64, 2016.

9. Zhou CY, Dong YP, Sun X, Sui X, Zhu H, Zhao YQ, Zhang YY, Mason C, Zhu Q and Han SX: High levels of serum glypican-1 indicate poor prognosis in pancreatic ductal adenocarcinoma. Cancer Med 7: 5525-5533, 2018. 
10. Livak KJ and Schmittgen TD: Analysis of relative gene expression data using real-time quantitative PCR and the 2(-Delta Delta C(T)) method. Methods 25: 402-408, 2001.

11. Siegel RL, Miller KD and Jemal A: Cancer statistics, 2017. CA Cancer J Clin 67: 7-30, 2017.

12. Moon S, Yeon Park S and Woo Park H: Regulation of the Hippo pathway in cancer biology. Cell Mol Life Sci 75: 2303-2319, 2018.

13. Zahn LM: Effects of the tumor microenvironment. Science 355 $1386-1388,2017$

14. Willatt J, Ruma JA, Azar SF, Dasika NL and Syed F: Imaging of hepatocellular carcinoma and image guided therapies-how we do it. Cancer Imaging 17: 9, 2017.

15. Cui S, Leyva-Vega M, Tsai EA, EauClaire SF, Glessner JT, Hakonarson H, Devoto M, Haber BA, Spinner NB and Matthews RP: Evidence from human and zebrafish that GPC1 is a biliary atresia susceptibility gene. Gastroenterology 144: 1107-1115.e3, 2013.

16. Qiao D, Yang X, Meyer K and Friedl A: Glypican-1 regulates anaphase promoting complex/cyclosome substrates and cell cycle progression in endothelial cells. Mol Biol Cell 19: 2789-2801, 2008.

17. Zeng Y and Liu J: Role of glypican-1 in endothelial NOS activation under various steady shear stress magnitudes. Exp Cell Res 348: 184-189, 2016.

18. Ebong EE, Lopez-Quintero SV, Rizzo V, Spray DC and Tarbell JM: Shear-induced endothelial NOS activation and remodeling via heparan sulfate, glypican-1, and syndecan-1. Integr Biol (Camb) 6: 338-347, 2014.

19. Kayed H, Kleeff J, Keleg S, Jiang X, Penzel R, Giese T, Zentgraf $\mathrm{H}$, Büchler MW, Korc M and Friess H: Correlation of glypican-1 expression with TGF-beta, BMP, and activin receptors in pancreatic ductal adenocarcinoma. Int J Oncol 29: 1139-1148, 2006.

20. Lund ME, Campbell DH and Walsh BJ: The role of glypican-1 in the tumour microenvironment. Adv Exp Med Biol 1245: 163-176, 2020.
21. Wilson NH and Stoeckli ET: Sonic hedgehog regulates its own receptor on postcrossing commissural axons in a glypican1-dependent manner. Neuron 79: 478-491, 2013.

22. Kleeff J, Ishiwata T, Kumbasar A, Friess H, Büchler MW, Lander AD and Korc M: The cell-surface heparan sulfate proteoglycan glypican-1 regulates growth factor action in pancreatic carcinoma cells and is overexpressed in human pancreatic cancer. J Clin Invest 102: 1662-1673, 1998.

23. Kleeff J, Wildi S, Kumbasar A, Friess H, Lander AD and Korc M: Stable transfection of a glypican-1 antisense construct decreases tumorigenicity in PANC-1 pancreatic carcinoma cells. Pancreas 19: 281-288, 1999.

24. Ding K, Lopez-Burks M, Sánchez-Duran JA, Korc M and Lander AD: Growth factor-induced shedding of syndecan-1 confers glypican-1 dependence on mitogenic responses of cancer cells. J Cell Biol 171: 729-738, 2005.

25. Lu H, Niu F, Liu F, Gao J, Sun Y and Zhao X: Elevated glypican-1 expression is associated with an unfavorable prognosis in pancreatic ductal adenocarcinoma. Cancer Med 6: 1181-1191, 2017.

26. Weber C: Biomarkers: The challenge to find biomarkers for the early detection of pancreatic cancer. Nat Rev Gastroenterol Hepatol 12: 427, 2015.

27. Duan L, Hu XQ, Feng DY, Lei SY and Hu GH: GPC-1 may serve as a predictor of perineural invasion and a prognosticator of survival in pancreatic cancer. Asian J Surg 36: 7-12, 2013.

28. Witkiewicz AK, McMillan EA, Balaji U, Baek G, Lin WC, Mansour J, Mollaee M, Wagner KU, Koduru P, Yopp A, et al: Whole-exome sequencing of pancreatic cancer defines genetic diversity and therapeutic targets. Nat Commun 6: 6744, 2015.

29. Edge SB, Byrd DR, Compton CC, Fritz AG, Greene FL and Trotti A (eds): AJCC Cancer Staging Manual (7th edition). Springer, New York, NY, 2010

This work is licensed under a Creative Commons Attribution-NonCommercial-NoDerivatives 4.0 International (CC BY-NC-ND 4.0) License. 